\title{
Structural transitions and energy use: a decomposition analysis of Portugal 1995-2010
}

\section{Zeus Guevara \& João F. D. Rodrigues}

To cite this article: Zeus Guevara \& João F. D. Rodrigues (2016) Structural transitions and energy use: a decomposition analysis of Portugal 1995-2010, Economic Systems Research, 28:2, 202-223, DOI: 10.1080/09535314.2016.1157456

To link to this article: http://dx.doi.org/10.1080/09535314.2016.1157456

View supplementary material \lceil

曲 Published online: 21 Mar 2016.

Submit your article to this journal $\pi$

Џll Article views: 108

Q View related articles ¿

View Crossmark data ־

Citing articles: 2 View citing articles 


\title{
Structural transitions and energy use: a decomposition analysis of Portugal 1995-2010
}

\author{
Zeus Guevaraa, ${ }^{\mathrm{a}}$ (1) and João F. D. Rodrigues ${ }^{\mathrm{C}}$ (]) \\ ${ }^{a}$ Instituto Superior Técnico, Universidade de Lisboa, Lisbon, Portugal; ${ }^{b}$ Center for Sustainable Energy \\ Systems, Universidade of Lisboa, Lisbon, Portugal; ' Institute of Environmental Sciences (CML), Leiden \\ University, Leiden, The Netherlands
}

\begin{abstract}
The Portuguese energy sector changed substantially during the period 1995-2010, with the introduction of natural gas and a larger renewable energy production. During the same period, the country also continued the shift to a service economy. By 2005, these two transitions led to a large increase in primary energy use (PEU), followed by a significant decline until 2010. The goal of this paper is to identify the main driving factors of changes in the Portuguese PEU through structural decomposition analysis. To do so we build a novel hybrid model with a detailed description of the energy sector in physical units, and a coarser description of the rest of the economy in monetary units. The results show that the main drivers were final demand (increasing PEU) and the direct energy intensity (decreasing PEU); while the energy and economic transitions also contributed to decrease PEU, although to a lesser extent.
\end{abstract}

\section{ARTICLE HISTORY}

Received 13 November 2014 In final form 19 February 2016

\section{KEYWORDS}

Structural decomposition analysis; primary energy use; Portugal; energy transition; energy input-output analysis

\section{Introduction}

The European Union (EU) is currently committed to increase the share of energy consumption produced from renewable resources to $20 \%$ by the year 2020 (EU, 2009; Amorim et al., 2010; Haas et al., 2011; Brown, 2013). In this respect, Portugal has achieved an outstanding progress, increasing from 15\% in 1995 to 24\% in 2010 (DGEG, 2012). Because of this fact, Portugal has the potential to become a role model for many countries, including major economies such as China and the USA, as pointed out by Heer and Langniß (2007) and Rosenthal (2010).

The Portuguese energy sector has evolved substantially with the implementation of large renewable power generation projects, along with the introduction of natural gas imports from Algeria in 1997. From 1995 to 2010 Portugal increased its renewable share in total electricity generation from $29 \%$ to $54 \%$ (IEA, 2011; DGEG, 2014a,b). During this time the use of natural gas in the industrial, services and residential sectors increased by $9 \%, 5 \%$ and 4\%, respectively (DGEG, 2012). Although these changes were significant, the overall energy performance of the country was middling (Henriques, 2011). Primary energy use

\footnotetext{
CONTACT Zeus Guevara zguevara@iiec.unam.mx

(C) Supplemental data for this article can be accessed here. http://dx.doi.org/10.1080/09535314.2016.1157456
} 
(PEU) increased rapidly until 2005 after which it started to reduce (EUROSTAT, 2015b; IEA, 2011). Both primary energy intensity (PEU over gross domestic product) and efficiency of end-use energy technologies remained almost constant during most of the period under study (DGEG, 2012; Serrenho et al., 2014, 2015; EUROSTAT, 2015c).

Why did the structural transition of the energy sector between 1995 and 2010 not result in an overall reduction in PEU and a better energy performance? One possible explanation might be that during the same period Portugal continued an economic structural transition from manufacturing into services, which had started in the 1980s (BdP, 2009; Henriques, 2011; EUROSTAT, 2014a).

The goal of the present paper is to identify the main drivers of change in total PEU in Portugal during the period of 1995-2010 through Structural Decomposition Analysis (SDA), highlighting the relative contributions of energy and economic structural transitions.

Decomposition analysis is a procedure that helps identify the underlying factors behind changes in aggregate indicators of the economy, e.g. energy, environmental or socioeconomic indicators (Rose and Casler, 1996; Hoekstra and van den Bergh, 2003; Miller and Blair, 2009). This analysis can be used to evaluate the effectiveness of policy measures and determine future policy interventions (Hoekstra and van den Bergh, 2002; Liu and Ang, 2007). Particularly, SDA is a specific decomposition technique which is able to capture structural effects that arise from changes in the interlinkages between different sectors in the economy (Miller and Blair, 2009).

To the best of our knowledge, the present study is the first SDA of PEU in Portugal. Even though there is a small number of energy decomposition studies of Portugal, these are not about PEU but instead about energy intensity. These past studies have different degrees of sectoral aggregation, and time frames. In addition, most of them used the index decomposition approach (see Ang, 1999, 2004). Alcántara and Duarte (2004) examined how Portuguese energy intensity differed from the EU average in 1995, identifying the structural changes as the main factor of difference. Mendiluce et al. (2010) found that the small decrease in Portuguese primary energy intensity over the period 1995-2006 was entirely due to a decrease in direct energy intensity without any structural effect. Henriques (2011) examined the period 1971-2006 and found that structural changes from industry to services contributed to a decline of direct energy intensity, while technological changes contributed to an increase in direct energy intensity, both in manufacturing and in the service sector. Moreover, the rise in direct energy intensity in the industrial sector can be explained both by positive substructural changes and technological change, the latter mainly in the pulp and paper sector. Finally, in a study that encompasses other countries, Voigt et al. (2014) found that improvements between 1995 and 2007 were largely attributable to technological change, while structural change was less important.

Another novelty of the present study is that the proposed model, in contrast to conventional models, allows a decomposition of the effect of structural changes and efficiency gains separately in the energy sector and in the rest of the economy. Our model thus combines characteristics of the hybrid-unit model (Bullard and Herendeen, 1975) and of the direct impact coefficient model (Rose and Casler, 1996).

The paper proceeds as follows: Section 2 presents an empirical overview of the observed energy and economic transitions; Section 3 introduces the proposed decomposition model 
and reviews the theory of SDA; Section 4 describes the source data; Section 5 presents and discusses the results; and Section 6 presents final remarks.

\section{The energy and economic transitions in Portugal}

This section describes the energy and economic transitions that occurred in Portugal between 1995 and 2010 .

\subsection{Energy transition}

During the period under analysis, PEU increased by 10\%, from 847 to 993 PJ (Figure 1). This growth in PEU was marked by an initial upward trend, with a peak of 1179 PJ in 2005, followed by a solid decline until 2010 (IEA, 2011; EUROSTAT, 2015b).

The Portuguese primary energy mix started changing with the introduction of natural gas in 1997. This energy carrier represented a cleaner option than crude oil for power generation as well as a replacement for some oil products (e.g. fuel oil and LPG) for end uses. By 2010, natural gas accounted for $28 \%$ of total electricity generation (IEA, 2011; DGEG, 2014a,b). In addition, there was a steady growth of natural gas for direct energy consumption in the industrial, services and residential sectors (DGEG, 2012). Even though natural gas use is still relatively low in comparison to other European countries (Amador, 2010), it has helped diversify the primary energy mix and reduce the growth rate of $\mathrm{CO}_{2}$ emissions (Diakoulaki and Mandaraka, 2007; Arto et al., 2009; Robaina Alves and Moutinho, 2013).

Furthermore, there was a significant increase in renewable energy production. The electricity sector in particular underwent a large transition. In 1995 most electricity was generated from fossil fuels ( $40 \%$ coal and $31 \%$ oil), with the remaining demand met by hydroelectric power. However, by 2010, renewables reached $11 \mathrm{GW}$ of installed capacity and $54 \%$ of total electricity generation, while coal and oil accounted for only $18 \%$ of total generation (IEA, 2011; DGEG, 2014a,b). Notably, from 2005 to 2010, renewable energy

Figure 1. (Colour online) Total PEU.

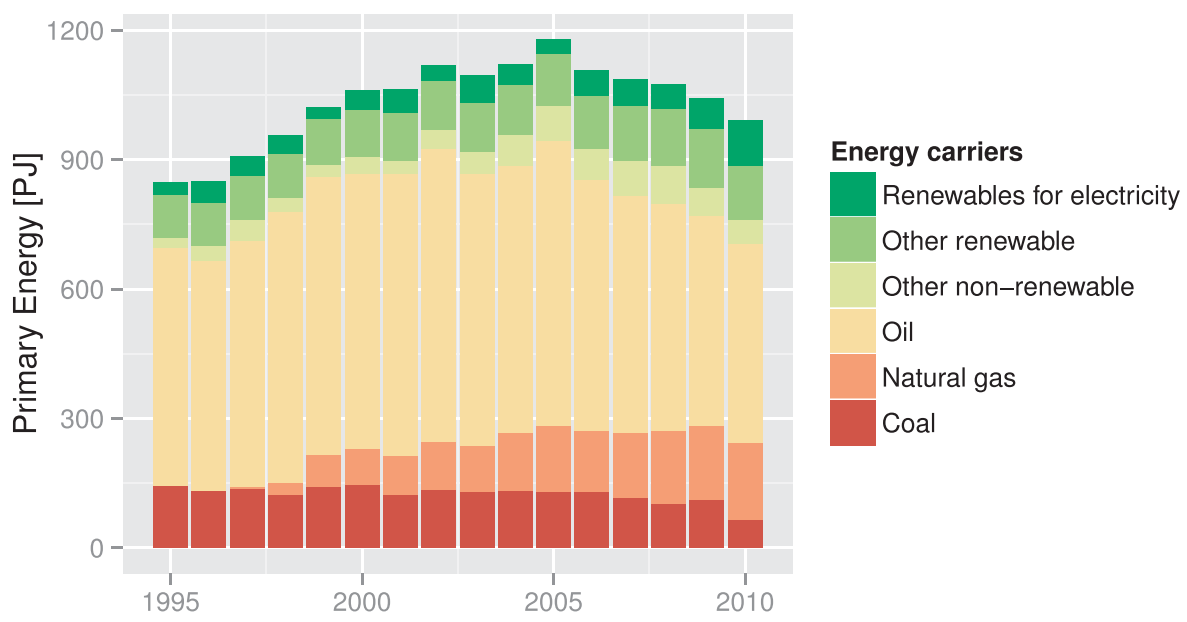


production increased by $50 \%$, from 153 to 232 PJ, reaching a $24 \%$ share of total primary energy supply.

These factors together with the decrease in overall energy demand after 2005 and the decline in coal use since 2000 , led to a rather different primary energy mix in 2010, when compared to 1995.

The PEU to meet final energy demand by households increased from $328.3 \mathrm{TJ}$ in 1995 to $451.4 \mathrm{TJ}$ in 2002, remained constant between 2002 and 2009, and decreased to $422.8 \mathrm{TJ}$ by 2010 . The main primary carrier contributing to this household PEU was oil (60-72\%), mainly because of the large demand of secondary oil products for household transport. The share of secondary oil products in final (as opposed to primary) energy use by households increased from a $56.9 \%$ in 1995 to $60.3 \%$ in 1999 and afterwards at $61.5 \% \pm 1.5 \%$ in 2000-2010. The share of Natural gas in household PEU exhibited a stable growth since its introduction in 1997, reaching a share of $9.75 \%$ in 2010 . However, the contribution of this carrier to household final energy use remained below 4\%. The share of electricity in the final energy use by households grew from $11 \%$ to $15.8 \%$ during the period under study. Finally, the consumption of oil for other uses and biomass also witnessed a decline.

The PEU associated with industrial direct energy demand grew from 518.8 to 716.6 TJ in the period 1995-2005 and later decreased to 569.8 TJ by 2010. In 1995, coal and oil had the largest shares (of $22 \%$ and 62\%, respectively), although by 2010 they had fallen substantially (to $8 \%$ and $33 \%$, respectively). By the end of the period oil remained the main predominant energy carrier although the share of natural gas reached $24 \%$, and the share of renewable primary carriers increased from $13 \%$ to $27 \%$.

As shown in Figure 2, primary energy intensity (PEU per unit of GDP) exhibited no significant variation from 1995 to 2005 (8.18 MJ/Euro $\pm 5 \%$ ). However, in the period 2005-2010, this value fell by 20.6\% (DGEG, 2012; EUROSTAT, 2015c).

Furthermore, improvements in end-use energy technologies were limited. The evolution of energy use efficiency has slowed since 1990 (Serrenho et al., 2014, 2015); and has been offset by the growing energy demands of private transportation and comfort in the service sector (Henriques, 2011; Serrenho, 2013).

Figure 2. Overall primary energy intensity.

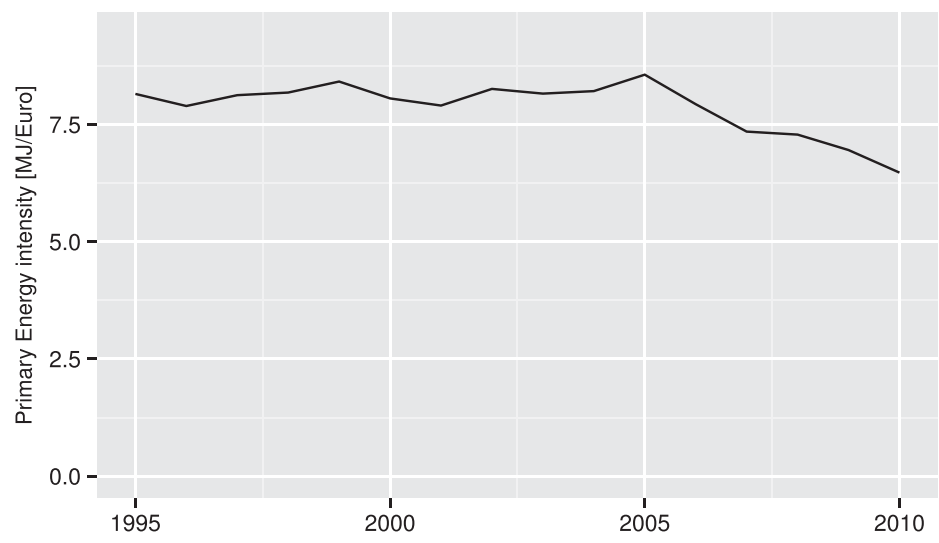


If we compare the evolution of the PEU of Portugal with other EU15 countries during this period, we find that before 2005 Portugal displayed patterns similar to those of Austria, Ireland, Greece, Luxembourg and Spain, with an increase of more than $15 \%$ in PEU. In contrast, the other EU15 countries had smaller increases. However, after 2005 Portugal had one of the sharpest declines among the EU15 countries (IEA, 2011; DGEG, 2012; EUROSTAT, 2015b). Also, only Portugal and Spain showed no decline in primary energy intensity before 2005, although afterwards the Portuguese primary energy intensity did fall, eventually converging to the European average by 2010 (Mendiluce et al., 2010; Robaina Alves and Moutinho, 2013; EUROSTAT, 2015c). In terms of the evolution of energy use efficiency, Portugal performed better than Greece and Ireland but fared significantly worse than Belgium, Finland, Spain and Sweden (Serrenho et al., 2015).

The energy transition in the country was mainly driven by climate change policy, in compliance with international and EU energy directives rather than by endogenous change (APA, 2012; Carvalho et al., 2014). As a result of the Kyoto Protocol, Portugal issued the National Program for Climate Change (PNAC) in 2001 - updated in 2004 and 2006 (Pinheiro Alves and Oliveira da Silva, 2011; Carvalho et al., 2014). This PNAC was accompanied by the National Energy Strategy (ENE) issued in 2003 which was updated first in 2005 and again in 2010 (ADENE, 2015). The 2005 update of the ENE raised the targets for energy efficiency and renewable energy from those set in the first ENE (IEA, 2009; Carvalho et al., 2014) because at the time the Portuguese greenhouse gas emissions were far above from the Kyoto protocol's target (IEA, 2009; EEA, 2013; Carvalho et al., 2014). To comply with the ENE and EU energy directives, Portugal issued the National Energy Efficiency Action Plan (PNAEE) and the National Renewable Energy Action Plan (PNAER) in 2008, updated in 2013 (IEA, 2009; Pinheiro Alves and Oliveira da Silva, 2011; ADENE, 2015). Other policies and regulations that also contributed to the energy transition were the Iberian Energy market created in 2004, the Management System of Intensive Energy Consumption (RGCE) issued in 2008 (which replaced an outdated energy efficiency policy from 1983), and the Portuguese Carbon Fund set in 2006 (IEA, 2009; Carvalho et al., 2014).

According to some authors, e.g. Amador (2010), EU (2014a), EU (2014b), Filipović et al. (2015) and Varandas Ferreira (2013), variations in the international prices of crude oil and natural gas also contributed to the energy transition in combination with policy. World crude oil prices witnessed a sharp increase after 2001, they were over 4 times higher in 2010 than in 2000 (EIA, 2014). On the other hand, natural gas prices almost doubled between 2004 and 2010, with a large price shock in 2008 (IEA, 2012; EUROSTAT, 2014b). Portugal has a high level of energy dependence and is vulnerable to energy price shocks (Carvalho et al., 2014). This pushed the country to pursue even stronger policy goals in energy efficiency and renewable energy (Amador, 2010; Robert and Lennert, 2010).

\subsection{Economic transition}

In the period 1995-2010, the Portuguese economy continued a transition toward a service economy that had begun in the 1980's (Henriques, 2011; Serrenho et al., 2015). To illustrate these structural changes, Figure 3 shows the distribution of the Portuguese GDP by sector. Following Weber (2009), the figure shows manufacturing divided into energy-intensive (pulp and paper, basic chemical and nonmetallic mineral industries) and 
Figure 3. (Colour online) GDP by industry.

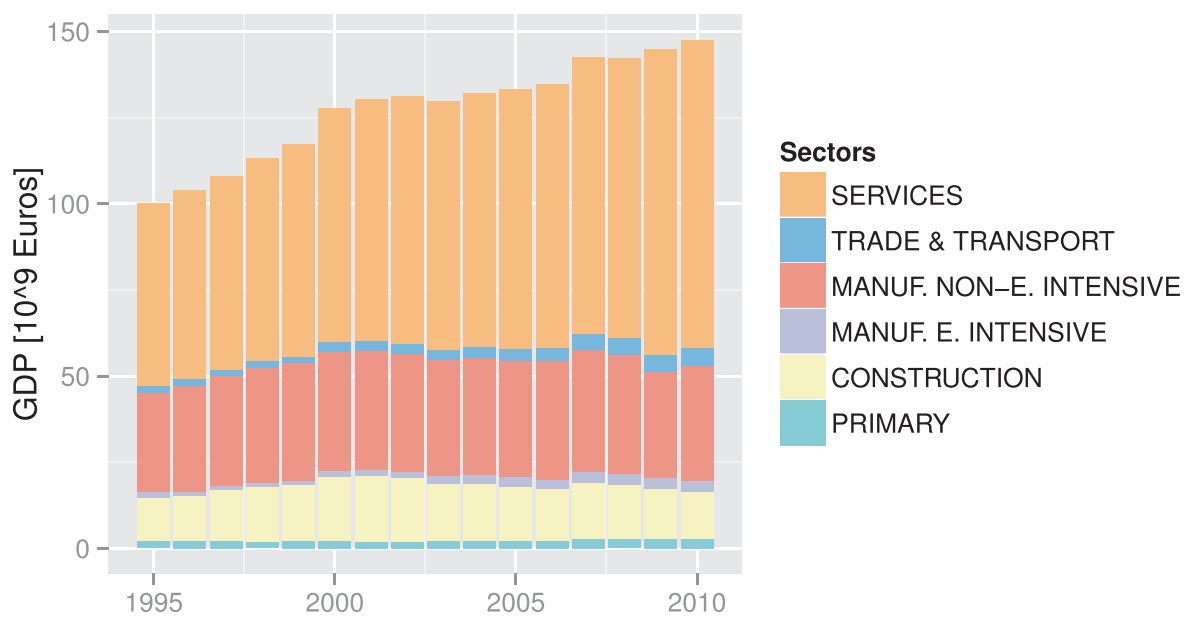

non-energy-intensive manufacturing (the remaining industries). In addition, the primary sector consists of agriculture, fishing, forestry and related activities.

In 1995, services already had the largest share of GDP (53\%), which continued to grow until reaching $60.5 \%$ in 2010 . Trade and transport more than doubled in size from 1.9 to 5.3 billion euros, which suggests an increase in connectivity in the country, although the GDP share of transport and trade remained very small (max. 3.5\%). Another sector that experienced significant increases in size was energy-intensive manufacturing (1.5-3.2 billion euros), although its relative contribution to overall GDP remained small (max. 2.2\% of GDP share). On the other hand, non-energy-intensive manufacturing, construction and the primary sector experienced a reduction in their share of GDP (e.g. the share of nonenergy-intensive manufacturing fell from $28.8 \%$ to $22.5 \%$ ).

Table 1 presents the direct energy intensity of different industries. Direct energy intensity is the ratio of direct energy use and gross economic output, and is thus a metric of energy-economic performance.

Services performed poorly, with direct energy intensity increasing by $7 \%$. This pattern is explained by an increase in comfort-related energy use (e.g. heating and cooling) as pointed out by Henriques (2011). However, in 2004 the energy intensity of services peaked and started to decline at the same time as oil and natural gas prices soared (IEA, 2012; EIA, 2014). Trade and transport, energy-intensive manufacturing, and the primary sector experienced reductions in energy intensity (of $-59 \%,-41 \%$ and $-37 \%$, respectively). Finally, non-energy-intensive manufacturing witnessed only a slight decrease $(-8 \%)$.

Table 1. Industrial direct energy intensity in selected years (MJ/Euro).

\begin{tabular}{|c|c|c|c|c|c|c|}
\hline Sector & 1995 & 1998 & 2001 & 2004 & 2007 & 2010 \\
\hline Primary & 10.63 & 8.44 & 11.14 & 7.46 & 7.13 & 6.73 \\
\hline Construction & 2.30 & 2.37 & 2.19 & 2.16 & 1.64 & 1.69 \\
\hline Energy int. manufacturing & 77.39 & 132.33 & 80.44 & 61.16 & 46.97 & 45.57 \\
\hline Non-en. int. manufacturing & 2.41 & 2.36 & 2.33 & 2.38 & 2.20 & 2.23 \\
\hline Trade and transport & 29.13 & 34.36 & 26.69 & 23.99 & 17.83 & 12.08 \\
\hline Services & 0.87 & 1.14 & 1.24 & 1.43 & 1.15 & 0.93 \\
\hline
\end{tabular}


Since services and non-energy-intensive manufacturing account for $80-83 \%$ share of GDP and about half (40-47\%) of PEU associated with industrial direct energy demand, their poor energy performance outweighed the improvements in energy intensity of other sectors.

Energy policies such as the PNAEE and RGCE (including other policies that preceded them) influenced the energy intensity trend of the different industries (IEA, 2009; Pinheiro Alves and Oliveira da Silva, 2011). On the other hand, fluctuations in energy prices could have also influenced the industrial energy performances as suggested by Amador (2010), EU (2014a), EU (2014b), Filipović et al. (2015) and Scholtens and Yurtsever (2012). Particularly, EU (2014a) pointed out that energy-intensive industries of EU countries are most exposed to increases in energy prices. However, EU (2014b) also showed that, in the period 1995-2009, improvements in energy efficiency caused by increases in energy prices were not large enough to offset the negative effects of high energy prices.

The integration of Portugal in the European Economic and Monetary Union, which bound the economy into a single EU currency, promoted further economic and structural changes such as the avoidance of internal monetary policy, increases in wages, and a larger focus in sectors with mainly undifferentiated products (BdP, 2009; Leite, 2010; AguiarConfraria et al., 2012). In addition, Portugal suffered a contraction in 2003 (BdP, 2009; Aguiar-Confraria et al., 2012) and the financial crisis of 2007-2009 (French et al., 2009; Farto and Morais, 2011; Gros, 2012; Lourtie, 2012), after which the country entered a macroeconomic adjustment process (Claessens et al., 2010; Costa, 2012; Rodrigues and Reis, 2012).

\section{Methodology}

This section describes the methodological framework of our proposed decomposition model. The complete model for the decomposition of PEU is presented in Section 3.3 and is composed by two linked sub-models: A sub-model of the energy sector in physical units (Section 3.1) and a sub-model of the rest of the economy in monetary units (Sections 3.2). Finally, Section 3.4 describes the general form of the SDA used in this study.

\subsection{Energy sector}

The energy sector model is based on Portuguese energy balances (DGEG, 2012). These balances were arranged to conform to a supply and use table (SUT) framework (Suh, 2009; Rodrigues and Rueda-Cantuche, 2013; EUROSTAT, 2014a), which consists of a set of $n_{T}$ energy technologies (e.g. oil refineries or wind power generation) and $n_{E}$ different types of energy carriers (e.g. crude oil or electricity).

The total of $n_{E}$ energy carriers are classified into three categories:

(1) $n_{W}$ primary energy carriers, endogenous and imported raw energy sources for conversion into non-energy, and secondary energy carriers (e.g. wind or crude oil);

(2) $n_{C}$ secondary energy carriers, energy products for direct use of economic sectors (e.g. electricity or fuel oil); and

(3) $n_{N}$ non-energy carriers, outputs of the energy sector with non-energy uses (e.g. lubricant or paraffin). 
Within this framework, energy technologies use primary, secondary and non-energy carriers in energy conversion processes, and deliver secondary and non-energy carriers to a set of $n_{R}$ non-energy industries of the rest of the economy (ROE industries), to final consumers and to other energy technologies for further processing.

Under these considerations, an energy analogue of the product-by-industry input-output approach (EUROSTAT, 2008b; Miller and Blair, 2009) is built, as described in the supplementary material. This leads to the final form of the energy component of our model, which accounts for the transformation between total PEU and the use of secondary energy by ROE industries (Equation 1), and final consumers (Equation 2). ${ }^{1}$

$$
\begin{aligned}
\mathbf{p}^{S} & =\mathbf{L}^{E} \mathbf{C}^{E} \mathbf{s}^{E}, \\
\mathbf{p}^{H} & =\mathbf{L}^{E} \mathbf{c}^{E} s^{H},
\end{aligned}
$$

where

- Vector $\mathbf{s}^{E}$ of length $n_{R}$ is the ROE energy demand factor, i.e. the total demand (in energy units) of secondary energy by ROE industries.

- Scalar $s^{H}$ is the final energy demand factor.

- Matrix $\mathbf{C}^{E}$ of size $n_{E} \times n_{R}$ is the (a dimensional) ROE energy demand composition factor. Element $C_{i j}^{E}$ is the fraction of the energy demand by ROE industry $j$ which is provided by energy carrier $i$ (e.g., the share of natural gas in the energy use of the chemical industry).

- Vector $\mathbf{c}^{E}$ of length $n_{E}$ is the (a dimensional) final energy demand composition factor. Element $c_{i}^{E}$ is the fraction of the final energy demand which is provided by energy carrier $i$ (e.g. the share of electricity in total energy use by final consumers).

- Matrix $\mathbf{L}^{E}$ of size $n_{W} \times n_{E}$ is the (a dimensional) total primary energy requirements factor. Element $L_{i j}^{E}$ is the primary energy consumption of primary energy carrier $i$ which is required to generate a unit of energy carrier $j$ for ROE and final energy demand (e.g. the amount of natural gas required by thermoelectric power plants to produce a $\mathrm{kWh}$ of electricity).

- Vectors $\mathbf{p}^{S}$ and $\mathbf{p}^{H}$ of length $n_{W}$ are the vectors of PEU associated with energy demand by ROE industries and final consumers, respectively.

This sub-model presents a complete description of the energy flows in the economy, measured in physical units.

\subsection{The rest of the economy}

The sub-model of rest of the economy is also built according to the product-by-industry input-output approach (EUROSTAT, 2008b; Miller and Blair, 2009), in which goods and services (e.g. publishing or rubber) are classified into a set of $n_{P}$ non-energy commodities or products (ROE products). There is consumption by a set of $n_{S} \mathrm{ROE}$ industries (e.g. paper or agriculture) and by $n_{F}$ categories of final demand (households, non-profit organizations, government, capital formation and exports). Goods and services can be produced

\footnotetext{
${ }^{1}$ In the following expressions, italic denotes a scalar (e.g. $n_{R}$ and $s^{H}$ ), lowercase bold denotes a vector (e.g. $c^{E}$ ), and uppercase bold amatrix (e.g. $\left.\mathbf{L}^{E}\right)$. Vectors are in column format and' denotes transposition.
} 
domestically or imported, and industries additionally purchase primary inputs such as labor and capital.

It is important to note that energy industries and products are not considered in this sub-model in monetary terms because in a hybrid model it is important to avoid doublecounting, so to make sure that the same flow is not being considered twice, in both monetary and physical units (Strømman et al., 2009).

The resulting decomposition model is a set of coefficients whose product connects the total economic output in each ROE industry to the total final demand for ROE products:

$$
\mathbf{x}^{M}=\mathbf{L}^{M} \mathbf{C}^{M} \mathbf{s}^{M},
$$

where

- Vector $\mathbf{s}^{M}$ of length $n_{F}$ is the final ROE product demand factor, i.e. the total demand for products of ROE industries (in monetary terms) of each final demand category.

- Matrix $\mathbf{C}^{M}$ of size $n_{P} \times n_{F}$ is the (a dimensional) final ROE product demand composition factor. Element $C_{i j}^{M}$ is the share of ROE product $i$ which is consumed by final demand category $j$ (e.g. the share of agricultural products in total exports).

- Matrix $\mathbf{L}^{M}$ of size $n_{S} \times n_{P}$ is the (a dimensional) total ROE product requirements factor. Element $L_{i j}$ is the total output of ROE industry $i$ which is required to generate one unit of ROE product $j$ for final demand (e.g. the amount of wood purchases required to produce a unit of construction services).

- Vector $\mathbf{x}^{M}$ of length $n_{S}$ is the total monetary output of each ROE industry.

The model of the rest of the economy does not present a complete description of all monetary flows in the economy because transactions of energy carriers are omitted (see above).

\subsection{Link between sub-models and the complete decomposition model}

The energy and the rest of the economy sub-models are connected by the concept of direct energy intensity, i.e. the direct energy use required to produce a unit of economic output.

The direct energy intensity factor $\left(\mathbf{E}^{S}\right)$ is a matrix of size $n_{R} \times n_{S}$, whose element $E_{i j}^{S}$ is the direct energy consumption (in energy units) of industry $i$ of ROE energy demand (described by $\mathbf{s}^{E}$ ) which is required to generate one unit of output (in monetary units) of a correspondent industry $j$ of the rest of the economy (described by $\mathbf{x}^{M}$ ).

$$
E_{i j}^{S}=\frac{s_{i}^{E}}{x_{j}^{M}} .
$$

If the industrial classification of ROE energy demand of the energy sub-model is equivalent to the classification of ROE industries of the rest of the economy sub-model then $\mathbf{E}^{S}$ is a diagonal matrix.

$\mathbf{E}^{S}$ establishes a link between the energy sector (Equation 1) and the rest of the economy (Equation 3) and closes the decomposition model of PEU associated with the final demand 
for products of ROE industries as

$$
\mathbf{p}^{S}=\mathbf{L}^{E} \mathbf{C}^{E} \mathbf{E}^{S} \mathbf{L}^{M} \mathbf{C}^{M} \mathbf{s}^{M}
$$

Furthermore, the expression of PEU associated with final energy demand (which in this work corresponds to household energy demand - not including energy exports) in Equation 2 was extended, as e.g. in Wachsmann et al. (2009) or Wood (2009a), by expanding the term $s^{H}$ :

$$
\mathbf{p}^{H}=\mathbf{L}^{E} \mathbf{c}^{E} b^{H} a^{H}
$$

where there are the following terms (except matrix $\mathbf{L}^{E}$ and vector $\mathbf{c}^{E}$, which are described in Section 3.1):

- Scalar $a^{H}$ is the total household energy expenditure in monetary terms.

- Scalar $b^{H}$ is the aggregate energy price faced by households, i.e. total household energy demand (in energy units) per household energy expenditure (in monetary units).

The proposed model combines characteristics of the two conventional energy decomposition models: The hybrid-unit model (Bullard and Herendeen, 1975; Miller and Blair, 2009) and the direct impact coefficient model (or intensity factor model) (Rose and Casler, 1996). On the one hand, the present model has a hybrid-unit system, i.e. physical units for the energy sector and monetary units for the rest of the economy, and is able to connect final demand for ROE products and energy products with PEU. On the other hand, the model corresponds to the direct impact coefficient model if the elements $\mathbf{L}^{E}$ and $\mathbf{C}^{E}$ in are removed or aggregated to $\mathbf{E}^{S}$ in Equation 5. Nevertheless, in contrast to these conventional models, it is able to distinguish the effect of structural changes in the energy sector (through $\mathbf{L}^{E}$ ) from structural changes in the rest of the economy (through $\mathbf{L}^{M}$ ).

The scope of the present study is concerned with the accounting of the PEU associated with final demand within Portugal. Hence, PEU associated with the direct energy consumed within Portugal to generate exports of ROE products is taken into account. However, the PEU associated with exports of energy carriers and the PEU that occurs abroad to generate Portuguese imports of ROE products are not taken into account.

\subsection{Structural decomposition analysis}

Consider an endogenous variable which is defined as the product of $n$ (multidimensional) exogenous factors. Decomposition analysis is a methodology which decomposes the total change in the endogenous variable as a sum of effects of changes in the exogenous factors (Rose and Casler, 1996; Hoekstra and van den Bergh, 2003, 2002).

SDA is the specific decomposition technique which accounts for the effects of changes in the intersectoral relationships in the economy based on the input-output framework (Miller and Blair, 2009). The advantage of SDA over other decomposition methodologies, such as index decomposition analysis (Ang, 2004), is that it provides more detailed results, although it also requires more complex data (Su and Ang, 2012a). SDA has been applied to energy consumption indicators since the 1980s (Hoekstra and van den Bergh, 2002) and it is now a widely recognized tool for policy analysis (Su and Ang, 2012a). 
In the present study we explore the decomposition of PEU as a function of final demand for ROE products (Equation 5) and for energy carriers (Equation 6). Given two reference years $t_{1}$ and $t_{2}$, the SDA explains the variation in PEU in this time frame, $\Delta \mathbf{p}=\mathbf{p}\left(t_{2}\right)-\mathbf{p}\left(t_{1}\right)$, as the sum of $n$ distinct factor coefficients:

$$
\begin{aligned}
\Delta \mathbf{p}^{S} & =\delta \mathbf{L}^{E}+\delta \mathbf{C}^{E}+\delta \mathbf{E}^{S}+\delta \mathbf{L}^{M}+\delta \mathbf{C}^{M}+\delta \mathbf{s}^{M}, \\
\Delta \mathbf{p}^{H} & =\delta \mathbf{L}^{E}+\delta \mathbf{c}^{E}+\delta \mathbf{b}^{H}+\delta \mathbf{a}^{H},
\end{aligned}
$$

where each factor coefficient $\delta \mathbf{X}$ is the contribution of changes in factor $\mathbf{X}$ to the observed variation in total primary energy consumption.

There are different mathematical techniques to determine the value of the factor coefficients in Equations 7 and 8. In this work we use the D\&L technique (Dietzenbacher and Los, 1998) that calculates the effect of each factor as the average of all equivalent decomposition forms. The D\&L technique was selected because it offers a complete decomposition (no residual term) and is zero-value and negative-value robust.

Dietzenbacher and Los (1998) show that the number of all decomposition forms is equal to $n$ !, where $n$ is the number of factors. In our case, at most $n=6$, and hence there are at most $6 !=720$ equivalent decomposition forms. These many forms make the formulation cumbersome and computer intensive. However, an important computational development of the D\&L technique was the combinatorial approach provided by Seibel (2003), based on previous work by De Haan (2001), which simplifies the formulation and reduces computational requirements. Therefore, in the present study, the values of the factor coefficients were obtained through Seibel's approach to the D\&L technique.

\section{Data}

This section reports the source data and the data processing required to perform the SDA. Section 4.1 and Section 4.2 describe the energy and economic data, respectively.

\subsection{Energy data}

Yearly energy supply and use tables were built from the Portuguese energy balances for the period 1995-2010 (DGEG, 2012), which were then used to build the energy decomposition factors Equation 1. The total primary energy requirements matrix $\left(\mathbf{L}^{E}\right)$ was obtained as a product-by-product matrix using the industry technology assumption as summarized in the supplementary material (Guo et al., 2009; Miller and Blair, 2009). Additional discussion on technology assumptions can be found elsewhere (ten Raa and Rueda-Cantuche, 2003; Suh, 2009; Weidema et al., 2009; Rodrigues and Rueda-Cantuche, 2013).

The energy SUTs have a classification of $n_{R}=24$ ROE industries of direct energy demand, $n_{T}=34$ energy technologies, and $n_{E}=38$ energy carriers, of which $n_{W}=14$ are primary energy carriers, $n_{C}=19$ are secondary energy carriers and $n_{N}=5$ non-energy carriers, which are listed in the supplementary material.

The set of ROE industries of direct energy demand in the energy sub-model differs from the set of industries in the sub-model of the rest of the economy since the classifications belong to different sources. In the description of rest of the economy, there are $n_{S}=47 \mathrm{ROE}$ industries, whereas in the direct energy demand described in the energy balances there are 
only $n_{R}=24$. Hence, the direct energy intensity matrix, $\mathbf{E}^{S}$, has dimensions $24 \times 47$ and performs the necessary aggregations and disaggregations to ensure that Equation 4 is valid for every pair $\left(s_{i}^{E}, x_{j}^{M}\right)$.

The energy balances present the aggregate of fuel uses for transportation by households and by the transport sector. However, the National Statistical Office provides detailed data on fuel uses for transportation, which distinguish the use by households and the transport sector for the whole period under study (INE, 2013). Therefore, in this work, the household demand for energy products includes the energy uses for private transportation.

There are two methods to account for the primary energy equivalent of electricity produced from renewable sources: the partial substitution method and the physical content method (UN, 1982; Bhattacharyya, 2011; IEA, 2014). The former transforms the flows of renewable electricity into the equivalent non-renewable primary energy that would be needed if the same amount of electricity had been produced by existing national thermoelectric power plants. The latter considers the physical content of the first usable energy form (i.e. electricity or heat) as the equivalent primary renewable energy. In this work, the physical content method is taken as the reference, because the partial substitution method is not recommended for countries with a large share of renewables such as Portugal (IEA, 2014)

Finally, the primary energy equivalent of imports of secondary energy products, which is a component of total energy demand, was calculated using the domestic technology assumption: imported energy carriers were assumed to have the same primary energy content of the equivalent domestically produced energy carrier.

\subsection{Economic data}

The main data source for the sub-model of the rest of the economy were the EUROSTAT Portuguese SUTs for the period 1995-2010 (EUROSTAT, 2014a).

In accordance with the SNA (UN, 1999, 2009), the EUROSTAT tables report intermediate and final use of total flows (imports and domestic products) in purchaser prices (with additional information on total imports, trade and transport margins and taxes less subsidies on products) and supply data in basic prices. The use data were converted from total flows in purchaser prices to domestic flows in basic prices and the industry technology assumption was used to obtain an industry-by-product technology matrix (EUROSTAT, 2008b; Miller and Blair, 2009).

The tables for the period 1995-2006 followed the CPA2002/NACE1.1 classification (respectively for products and industries) with $n_{S}=n_{P}=57$ ROE products and industries, whereas the tables for the period 2006-2010 followed the CPA2008/NACE2 classification, with $n_{S}=n_{P}=63 \mathrm{ROE}$ products and industries. We constructed a harmonized time-series (Wood, 2009b) in a common classification with $n_{S}=n_{P}=47$ elements based on EUROSTAT (2008a) and EUROSTAT (2009). The equivalence between the different classifications is reported in the supplementary material.

The harmonization of the two classification systems (NACE1 from 1995 to 2005 and NACE2.2 from 2006 to 2010) was performed mostly through aggregations. The only instance of disaggregation was sector C33 (repair and installation of machinery and equipment) of the NACE2 classification, which does not exist as an independent sector in classification NACE1.1, but is instead reported as a component of nine different types 
of machinery. Hence, in the 2006-2010 data NACE2 sector 33 was disaggregated among different machinery types in proportion to that machinery sector's share of total output. We performed a sensitivity analysis by exploring different assumptions concerning the disaggregation and found that they had a negligible effect on the results.

Furthermore, to perform the SDA it was necessary to convert the data from current to constant prices (Miller and Blair, 2009; Dietzenbacher and Temurshoev, 2012). Because the EUROSTAT source data are reported both in current, $c p$, and in previous year prices, pyp, a time-series in constant prices of 2002 was obtained by deflating/inflating the entire dataset with the appropriate chain indices (Dietzenbacher and Hoen, 1998; Jackson and Murray, 2004). Note: Some entries reported a zero value in the $p y p$ tables while the $c p$ value was different from zero. When such a situation occurred, the deflator used was the average deflator (across industries) for that commodity class as in the double deflation method (UN, 1993; Miller and Blair, 2009).

\section{Results and discussion}

This section presents a description and discussion of the results of the SDA of PEU in Portugal between 1995 and 2010.

\subsection{Drivers of change in the overall period}

Tables 2 and 3 present the SDA coefficients of changes in PEU associated with the final demand for ROE products and household demand for energy carriers in the period 1995-2010. In the case of ROE products, we report the SDA coefficients of each category of final demand separately.

There was a total increase in 145.5 PJ in PEU in the period under study, led by PEU increases associated with household demand for energy carriers, exports of ROE products and household demand for ROE products (94.5, 56.9 and 11.9 PJ, respectively). On the contrary, PEU associated with capital formation decreased while PEU changes associated with non-profit demand were negligible.

Table 2. SDA coefficients of PEU associated with the final demand for ROE products in 1995-2010.

\begin{tabular}{lrrrrrrr}
\hline Final demand category & \multicolumn{1}{c}{$\Delta \mathbf{p}^{S}$} & \multicolumn{1}{c}{$\boldsymbol{\Delta} \mathbf{L}^{E}$} & $\delta \mathbf{C}^{E}$ & $\delta \mathbf{E}^{S}$ & \multicolumn{1}{c}{$\delta \mathbf{L}^{M}$} & $\delta \mathbf{C}^{M}$ & $\delta \mathbf{s}^{M}$ \\
\hline Total & 51.1 & -79.6 & 29.0 & -172.4 & -67.7 & 1.9 & 339.9 \\
Households & 11.9 & -31.7 & 12.2 & -44.7 & -17.7 & -31.5 & 125.2 \\
Non-profits & 1.5 & -1.1 & 0.5 & -1.4 & 0.0 & -0.6 & 4.1 \\
Government & 10.6 & -9.4 & 4.1 & -10.2 & 3.6 & 4.0 & 18.4 \\
Capital formation & -29.8 & -13.2 & 5.3 & -37.3 & -9.8 & -13.2 & 38.4 \\
Exports & 56.9 & -24.1 & 6.8 & -78.8 & -43.8 & 43.1 & 153.8 \\
\hline
\end{tabular}

Table 3. SDA coefficients of PEU associated with the household demand for energy carriers in 1995-2010.

\begin{tabular}{cccccc}
\hline & $\Delta \mathbf{p}^{H}$ & $\delta \mathbf{L}^{E}$ & $\delta \mathbf{c}^{E}$ & $\delta \mathbf{b}^{H}$ & $\delta \mathbf{a}^{H}$ \\
\hline Total & 94.5 & -37.5 & 20.6 & -62.0 & 173.4 \\
\hline
\end{tabular}


Changes in the final demand for ROE products and in total household energy expenditures $\left(\delta \mathbf{s}^{M}\right.$ and $\left.\delta a^{H}\right)$ were the main drivers of PEU increases. The final demand categories of exports and household ROE demand contributed the most to the effect of $\mathbf{s}^{M}$.

Shifts in the composition of ROE energy demand, household energy demand and final demand for ROE products, $\delta \mathbf{C}^{E}, \delta \mathbf{c}^{E}$ and $\delta \mathbf{C}^{M}$ also contributed to increase PEU.

The value of $\delta \mathbf{C}^{E}$ and $\delta \mathbf{c}^{E}$ suggests that the share of energy carriers with large associated PEU in energy demand by ROE industries and households increased, e.g. larger use of thermoelectricity. The final demand category of household ROE demand accounted for most of the effect of $\mathbf{C}^{E}$. Moreover, the overall effect $\delta \mathbf{C}^{M}$ is negligible due to the counteracting contributions of the final demand categories of households ROE demand, with an increased share of ROE products with low associated PEU (e.g. computer and electronics), and of exports, where the opposite pattern holds true (Amador, 2012 found an increase in the energy content of ROE exports in Portugal in the period 1995-2005).

In contrast, improvements in direct energy intensity $\left(\delta \mathbf{E}^{S}\right)$, structural changes in the energy sector and the rest of the economy $\left(\delta \mathbf{L}^{E} \& \delta \mathbf{L}^{M}\right)$, and increases of aggregate energy prices to households $\left(\delta b^{H}\right)$ led to decreases in PEU.

The overall effect of the direct energy intensity, $\mathbf{E}^{S}$ represented the largest offsetting contribution to PEU increases. This means that the direct energy intensity trends of ROE industries (Table 1) led to a decrease in PEU. It is worth mentioning that the effect of $\mathbf{E}^{S}$ depends on other variables of the economy (according to Guevara, 2014) such as the technical efficiency of direct energy use; the price of ROE products; energy prices and the intensity of useful energy. However, the present SDA alone cannot disentangle the relative contributions of these variables to $\delta \mathbf{E}^{S}$.

The large decreasing effect of structural change in energy technology, $\delta \mathbf{L}^{E}$ on PEU was brought about by significant changes in the energy sector (i.e. a larger share of renewable power generation and improvements in primary-to-secondary conversion efficiencies). On the other hand, the structural changes of the rest of the economy, $\delta \mathbf{L}^{M}$, for example, the transition into a service economy, also had the effect of decreasing PEU since the service sector has the lowest energy intensity (see Table 1).

Increases in aggregate energy prices to households $\left(b^{H}\right)$ also contributed to decrease PEU associated with household demand for energy carriers. It is important to keep in mind that $b^{H}$ is a highly aggregated factor and hence, at this level of aggregation, the effect of changes in prices of individual energy carriers might have not been accounted for by $\delta b^{H}$ but instead by the effect of the composition of household energy demand, i.e. $\delta \mathbf{c}^{E}$. For a discussion of SDA aggregation issues, see, e.g. Su and Ang (2012b) and Dietzenbacher and Los (1998).

\subsection{Disaggregation in time}

We now present a breakdown of the SDA in two-year periods (plus an initial 3-year period for rounding), in order to gain a finer understanding of the effect of energy and economic transitions on PEU. Figure 4 presents the SDA results of the evolution of total PEU, i.e. PEU associated with the final demand for ROE products and household demand for energy carriers.

The intervals 1995-1998 and 1998-2000 were characterized by a sharp rise in PEU, mainly driven by final demand for ROE products, $\delta \mathbf{s}^{M}$ and total household energy 
Figure 4. (Colour online) SDA coefficients of the evolution of total PEU.

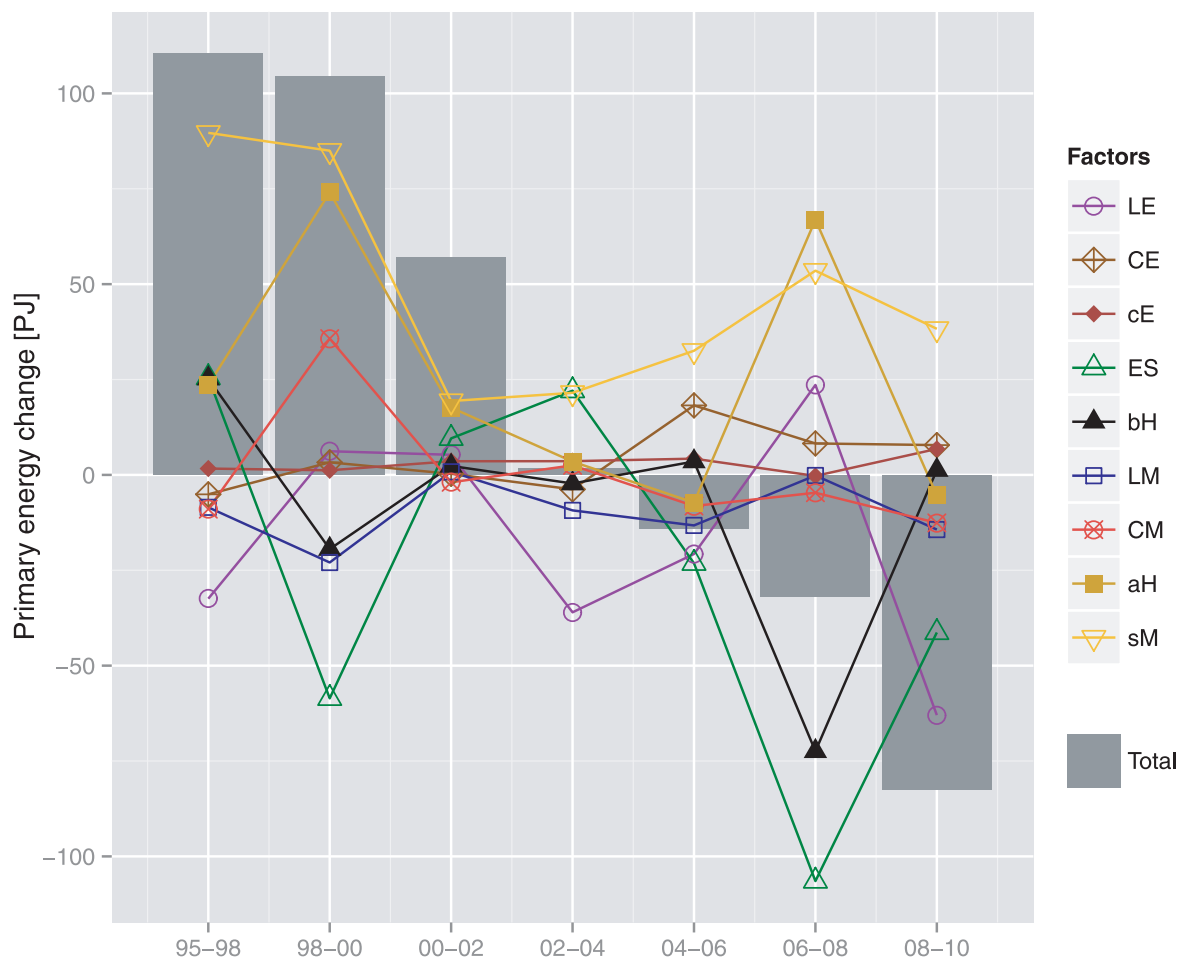

expenditure, $\delta a^{H}$. This coincided with a period of macroeconomic stability and rising private consumption that led to the adoption of the EU single currency in 1999 (BdP, 2009; Mata and Valério, 2003; Aguiar-Confraria et al., 2012). Between 1995 and 1998 structural changes in the energy sector, $\mathbf{L}^{E}$, contributed to decreasing PEU, as 1998 was a good year for hydroelectric production (DGEG, 2012). Moreover, aggregate energy prices to households, $b^{H}$, and the direct energy intensity, $\mathbf{E}^{S}$, had the effect of increasing PEU while other factors had only relatively minor effects. On the other hand, in the interval 1998-2000 we observe that (1) the composition of final demand for ROE products, $\delta \mathbf{C}^{M}$, contributed to increase PEU due to a shift of demand toward ROE products with larger associated PEU (e.g. land transport); (2) structural changes in the rest of the economy, $\delta \mathbf{L}^{M}$, contributed to decrease PEU, due to the expansion of services (Figure 3); (3) there was an improvement in direct energy intensity, $\delta \mathbf{E}^{S}$, caused by a productivity increase (BdP, 2009) and the use of more efficient technology (mainly explained by the introduction of natural gas for direct consumption) and (4) aggregate energy prices to households had the opposite effect as in 1995-1998, possibly caused by increases in oil energy prices in 1999 and 2000 (EIA, 2014).

After Portugal joined the euro, economic performance weakened and the economy suffered a contraction in 2003 (BdP, 2009; Aguiar-Confraria et al., 2012). Between 2000 and 2004 this poor economic performance led to a smaller effects of $\mathbf{s}^{M}$ and of $a^{H}$ and a change in direction of the effect of $\mathbf{E}^{S}$. The increase in direct energy intensity (see Table 1) reflects a loss in productivity and non-price competitiveness experienced during this interval (BdP, 2009; Farto and Morais, 2011). PEU growth slowed down in 2002-2004, mainly 
due to the effect of structural changes in the energy sector, $\delta \mathbf{L}^{E}$. For example, increases of renewable power generation and improvements in conversion efficiencies for thermoelectricity generation are observed due to increasing imports of natural gas (linked to the first version of the National Energy Strategy in 2003).

In the interval 2004-2006, PEU decreased slightly. Changes in final demand for ROE products, $\delta \mathbf{s}^{M}$, had the effect of increasing PEU, as did the composition of ROE demand for energy products, $\delta \mathbf{C}^{E}$. However, these effects were offset by improvements in direct energy intensity; advances in the energy sector; structural changes in the rest of the economy and reductions in total household energy expenditure. Possible explanations for the effect of $\mathbf{E}^{S}$ in this interval are the update of the National Energy Strategy in 2005 and the rise of oil and natural gas prices (EIA, 2014; EUROSTAT, 2014b) which could have forced the ROE industries to pursue improvements in productivity and energy efficiency (though relatively small, see Table 1 and Serrenho, 2013).

The interval 2006-2008 was characterized by a reduction of PEU. Possible explanations for the strong effect of the direct energy intensity, $\delta \mathbf{E}^{S}$, on reducing PEU are the impact of the 2007 financial crisis in the entire economy, high and rising energy prices (with a large oil and natural gas price shocks in 2008) and the launch of policies on industrial energy efficiency (such as the PNAEE and the RCGE). The combination of these occurrences could have forced the ROE industries to improve productivity and energy efficiency. Also, the strong effect of the aggregate energy price to households, $\delta b^{H}$, might be explained by international energy price shocks. Moreover, changes in the composition of ROE demand for energy carriers $\left(\delta \mathbf{C}^{E}\right)$ led to an increase in PEU through shifts in ROE energy demand, toward secondary energy carriers with larger associated PEU. Furthermore, $\mathbf{s}^{M}$ and $a^{H}$ had a large effect of increasing PEU, which implies increases in final demand for ROE products and in household energy expenditure despite the financial crisis. This puzzling result might be explained by rising private consumption due to a sense of partial recovery from the economic recession of 2003; and increased government spending, which reinforced the image of economic recovery (BdP, 2009; Leite, 2010). Lastly, changes in the energy sector had the effect of increasing PEU in this interval, which was caused by the deceleration of the rate of substitution of oil by natural gas for power generation; stagnant primaryto-secondary conversion efficiencies and a reduction of renewable electricity generation (2008 was a particularly bad year for hydroelectric production, DGEG, 2014b).

Finally, in the interval 2008-2010, the country again experienced an economic contraction, which led to a significant reduction of PEU. Changes in final demand for ROE products, $\delta \mathbf{s}^{M}$, contributed to increase PEU, though to a lesser extent than in the previous interval due to the reduction in private and government consumption (Claessens et al., 2010; Costa, 2012). Also the ROE and household demand for energy products, $\mathbf{C}^{E}$ and $\mathbf{c}^{E}$, with larger associated PEU increased. On the other hand, changes in the economic structure and in the demand composition of ROE products, $\mathbf{L}^{M}$ and $\mathbf{C}^{M}$, contributed to a slight reduction in PEU. In contrast to what happened in the previous interval, the effect of household energy expenditure, $\delta a^{H}$, led to a reduction in PEU, and the contribution of the aggregate energy price to households, $\delta b^{H}$, was negligible. The direct energy intensity had a significant effect of lowering PEU, although not as large as in 2006-2008. The evolution of $\delta \mathbf{E}^{S}$ was possibly influenced by the energy policies PNAEE and RGCE from 2008 (discussed in Section 2.1) and the relative drop of oil and natural gas prices in 2009 (IEA, 2012; EIA, 2014). In addition, transitions in the energy sector $\left(\delta \mathbf{L}^{E}\right)$ had 
a large effect of decreasing PEU due to an expansion of renewable power generation (DGEG, 2014b), which might have been induced by the PNAER policy from 2008 (also discussed in Section 2.1).

\section{Conclusions}

In this paper, we performed an SDA to identify the main driving factors of the trend of PEU in Portugal between 1995 and 2010. In particular, our focus was to understand the relative contribution of the substantial energy and economic transitions that the country underwent during this period.

We proposed a novel decomposition model which allows the accounting for the structural changes of the energy sector and the rest of the economy separately. This model combines features of the two conventional SDA models applied to energy studies (the direct impact coefficient and the hybrid-unit models), and enables a better understanding of the role of energy and economic transitions in PEU.

In the period under study there was an overall increase of $17 \%$ in PEU with an increase of $35 \%$ from 1995 to 2003 and a decrease of $18 \%$ from 2003 to 2010.

The SDA showed that the major driving factor leading to an increase in PEU was the final demand for non-energy products. This factor was especially important before the year 2000, a period during which the country enjoyed thriving economic growth. After that year, this factor had a lower effect on PEU mainly due to weak economic performance.

The main driving factor leading to a reduction in PEU were improvements in direct energy intensity (direct energy use per gross output), achieved through, for example, productivity gains and technological progress. These improvements were influenced by the international crisis of 2007-2009; climate change and energy efficiency policies; and high prices of oil and natural gas.

PEU associated with household demand for energy carriers increased. Total household energy expenditures had the largest effect on this PEU increases followed by the effect of the composition of household energy demand. These effects were partially offset by variations in the aggregate price of energy carriers faced by households and structural changes in the energy sector.

The main goal of the present study was the assessment of the relative contribution of energy and economic transitions to PEU. On the one hand, the economic transition toward a service economy had the effect of reducing PEU at every interval of the period under study due to the relative growth of industries with lower-than-average direct energy intensity. On the other hand, the energy transition had the overall effect of reducing PEU, which is explained by the expansion of renewable energy production and the adoption of natural gas. However, in 2000-2002 and 2006-2008, structural changes in the energy sector had the effect of increasing PEU as a result of lower-than-average rainfall, which limited hydroelectricity production.

It is also worth noting that structural changes in the energy sector exhibited an overall larger contribution to PEU than structural changes in the rest of the economy. We can thus infer that the energy transition had a higher impact in PEU than economic transition.

The present work gives insight on the effectiveness of some energy policies. As described, there were important changes to the energy regulation in Portugal motivated by climate change-related international directives. The energy performance of the country 
after 2005 reflects a certain degree of effectiveness of the National Energy Strategy from 2005 and of subsequent policies such as the Management System of Intensive Energy Consumption, the National Energy Efficiency Action Plan and the National Renewable Energy Action Plan. The SDA results suggest that these policies have had a positive impact in the economy and that continuing the current strategy could provide additional benefits. Because of this, Portuguese energy policies can provide guidance to policy-makers of other European countries, particularly those that lag behind in renewable electricity generation (in 2014, 16 of the EU28 countries had a lower renewable share in electricity generation than Portugal had in 1995, IEA, 2011; EUROSTAT, 2015a).

Furthermore, this study can also help Portuguese policy-makers identify areas of improvement for the current policies, as shown in the following examples: (1) the estimated effect of the composition of end-use energy demand (by industries and households) indicates that the National Energy Efficiency Action Plan should provide incentives to encourage a shift from energy carriers with high to low PEU content; (2) the pattern of the effect of the direct energy intensity suggests that the Management System of Intensive Energy Consumption should be modified to also include industries with low energy intensity and (3) the fact that the effect of structural changes in the energy sector was mainly determined by the evolution of renewables for electricity generation implies that the National Renewable Energy Action Plan should improve the incentives to other renewables.

Nevertheless, the present study cannot provide a detail analysis of the impacts of particular policies in the trends of energy and GHG emissions, doing so constitutes a direction of further research. As another direction of further research, this study can be extended to take into account the role of the structure of international trade as driver of PEU change. This could be achieved by extending the analysis from the national to the multi-regional case, as done by Arto and Dietzenbacher (2014) or Xu and Dietzenbacher (2014) for carbon emissions.

\section{Acknowledgments}

We recognize the support of the MIT Portugal Program. We also thank the valuable comments and suggestions of Professors Paul Behrens, Tânia Sousa and Tiago Domingos.

\section{Disclosure statement}

No potential conflict of interest was reported by the authors.

\section{Funding}

This work was supported by the Fundação para a Ciência e a Tecnologia under Grant [SFRH/BD/51297/2010].

\section{ORCID}

Zeus Guevara (i) http://orcid.org/0000-0002-1254-8423

João F. D. Rodrigues (D) http://orcid.org/0000-0002-1437-0059 


\section{References}

ADENE. (2015) "Política energética". http://www.adene.pt/politica-energetica.

Aguiar-Confraria L., Alexandre F., and Pinho M.C. (2012) O Euro E O Crescimento Da Economia Portuguesa: Uma AnÁLise Contrafactual. Análise Social, XLVII, 298-321. (in Portuguese).

Alcántara V. and Duarte R. (2004) Comparison of Energy Intensities in European Union Countries: Results of A Structural Decomposition Analysis. Energy Policy, 32, 177-189.

Amador J. (2010) Energy Production and Consumption in Portugal: Stylized Facts. Lisbon, Banco de Portugal.

Amador J. (2012) Energy Content in Manufacturing Exports: A Cross-Country Analysis. Energy Economics, 34, 1074-1081.

Amorim F., Martins M.V.M., and Pereira da Silva P. (2010) A New Perspective to Account for Renewables Impacts in Portugal (Paper presented at the 7th International Conference on the European Energy Market, Madrid).

Ang B.W. (1999) Decomposition Methodology in Energy Demand and Environmental Analysis. Cheltenham, Edward Elgar.

Ang B.W. (2004) Decomposition Analysis for Policymaking in Energy: Which is the Preferred Method? Energy Policy, 32, 1131-1139.

APA. (2012) Roteiro Nacional de Baixo Carbono. Análise técnica das opções de transição para uma economia de baixo carbono competitiva em 2050. Technical report, Agência Portuguesa do Ambiente. (in Portuguese).

Arto I. and Dietzenbacher E. (2014) Drivers of the Growth in Global Greenhouse Gas Emissions. Environmental Science and Technology, 48, 5388-5394.

Arto I., Gallastegui C., and Ansuategi A. (2009) Accounting for Early Action in the European Union Emission Trading Scheme. Energy Policy, 37, 3914-3924.

BdP. (2009) A Economia Portuguesa no Contexto da Integração Económica, Financeira e Monetária. Lisbon, Banco de Portugal (in Portuguese).

Bhattacharyya S.C. (2011) Energy Economics: Concepts, Issues, Markets and Governance. Dundee, Springer.

Brown P. (2013) European Union Wind and Solar Electricity Policies: Overview and Considerations. Washington, DC, Congressional Research Service.

Bullard C.W. and Herendeen R.A. (1975) The Energy Cost of Goods and Services. Energy Policy, 3, 268-278.

Carvalho A., Schmidt L., Santos F.D., and Delicado A. (2014) Climate Change Research and Policy in Portugal. Wiley Interdisciplinary Reviews: Climate Change, 5, 199-217.

Claessens S., Dell'Ariccia G., Igan D., and Laeven L. (2010) Cross-Country Experiences and Policy Implications from the Global Financial Crisis. Economic Policy, 25, 267-293.

Costa H.A. (2012) From Europe as a Model to Europe as Austerity: The Impact of the Crisis on Portuguese Trade Unions. Transfer: European Review of Labour and Research, 18, 397-410.

De Haan M. (2001) A Structural Decomposition Analysis of Pollution in the Netherlands. Economic Systems Research, 13, 181-196.

DGEG. (2012) "Balanços energéticos (Online database)." http://www.dgeg.pt/.

DGEG. (2014a) "Potência instalada nas centrais produtoras de energia elétrica 2008-2012 (Online database).” http://www.dgeg.pt/.

DGEG. (2014b) "Produção bruta de energia elétrica (Online database)." http://www.dgeg.pt/.

Diakoulaki D. and Mandaraka M. (2007) Decomposition Analysis for Assessing the Progress in Decoupling Industrial Growth from CO2 Emissions in the EU Manufacturing Sector. Energy Economics, 29, 636-664.

Dietzenbacher E. and Hoen A.R. (1998) Deflation of Input-Output Tables from the User's Point of View: A Heuristic Approach. Review of Income and Wealth, 44, 111-122.

Dietzenbacher E. and Los B. (1998) Structural Decomposition Techniques: Sense And Sensitivity. Economic Systems Research, 10, 307-324.

Dietzenbacher E. and Temurshoev U. (2012) Input-output Impact Analysis in Current or Constant Prices: Does It Matter? Journal of Economic Structures, 1, 1-18. 
EEA. (2013) “Annual European Union Greenhouse Gas Inventory 1990-2011.” http://www.eea. europa.eu/data-and-maps/data/data-viewers/greenhouse-g ases-viewer.

EIA. (2014) “Crude oil prices: Europe brent spot price FOB (dollars per barrel)." http://www.eia.gov/. EU. (2009) Directive 2009/28/EC of the European Parliament and of the Council of 23 April 2009 on the Promotion of the Use of Energy from Renewable Sources and Amending and Subsequently Repealing Directives 2001/77/EC and 2003/30/EC. Official Journal of the European Union, 140, $16-62$.

EU. (2014a) Energy Costs and Competitiveness. Paris, European Commission.

EU. (2014b) Energy Costs and EU Industrial Competitiveness, Book Section 6. Paris, European Commission.

EUROSTAT (2008a) Correspondence Table NACE Rev. 2 - NACE Rev. 1.1. Luxembourg, European Commission.

EUROSTAT (2008b) Manual of Supply, Use and Input-output Tables. Luxembourg, European Commission.

EUROSTAT (2009) Correspondence Table CPA 2002 - CPA 2008. Luxembourg, European Commission.

EUROSTAT (2014a) “ESA 95: Supply, Use and Input-output Tables (Online database)." http://epp. eurostat.ec.europa.eu/portal/page/portal/esa95_supply_use_input_tables/data/workbooks.

EUROSTAT (2014b) “Gas Prices for Industrial Consumers (Online database).” http://epp.eurostat.ec. europa.eu/.

EUROSTAT (2015a) “Electricity Generated from Renewable Sources (Online database)." http://ec. europa.eu/eurostat/web/productsdatasets//tsdcc330.

EUROSTAT (2015b) "Primary Energy Consumption (Online database)." http://ec.europa.eu/ eurostat/web/productsdatasets//tsdcc120.

EUROSTAT (2015c) "Energy Intensity of the Economy (Online database)." http://ec.europa.eu/ eurostat/web/productsdatasets//tsdec360.

Farto M. and Morais H. (2011) A Crise Portuguesa, O Resgate Internacional E O Crescimento Económico: Notas E Reflexões. JANUS.NET e-journal of International Relations, 2, 124-132 (in Portuguese).

Filipović S., Verbič M., and Radovanović M. (2015) Determinants of Energy Intensity in the European Union: A Panel Data Analysis. Energy, 92, 547-555.

French S., Leyshon A., and Thrift N. (2009) A Very Geographical Crisis: The Making and Breaking of the 2007-2008 Financial Crisis. Cambridge Journal of Regions, Economy and Society, 2, 287-302.

Gros D. (2012) Macroeconomic Imbalances in the Euro Area: Symptom or Cause of the Crisis? CEPS Policy Brief, 266, 1-11.

Guevara Z. (2014) Three-Level Energy Decoupling: Energy Decoupling at the Primary, Final and Useful Levels of Energy Use. Ph.D. thesis, University of Lisbon, Lisbon.

Guo J., Lawson A.M., and Planting M.A. (2009) From Make-use to Symmetric I-O tables: An Assessment of Alternative Technology Assumptions (Paper presented at the 14th International Conference on Input-Output Techniques, pp. 1-6, Montreal).

Haas R., Panzer C., Resch G., Ragwitz M., Reece G., and Held A. (2011) A Historical Review of Promotion Strategies for Electricity from Renewable Energy Sources in EU Countries. Renewable and Sustainable Energy Reviews, 15, 1003-1034.

Heer K. and Langniß O. (2007) Promoting Renewable Energy Sources in Portugal: Possible Implications for China. Stuttgart, Centre for Solar Energy and Hydrogen Research.

Henriques S.T. (2011) Energy Transitions, Economic Growth and Structural Change: Portugal in a Long-Run Comparative Perspective. Lund Studies in Economic History. Vol. 54. Lund, Lund University.

Hoekstra R. and van den Bergh J.C.J.M. (2002) Structural Decomposition Analysis of Physical Flows in the Economy. Environmental and Resource Economics, 23, 357-378.

Hoekstra R. and van den Bergh J.C.J.M. (2003) Comparing Structural Decomposition Analysis and Index. Energy Economics, 25, 39-64.

IEA. (2009) Energy Policies of IEA Countries: Portugal. Paris, International Energy Agency. 
IEA. (2011) "Energy Balances of OECD Countries: Documentation for Beyond 2020 Files (Database)." http://stats.oecd.org/.

IEA. (2012) Natural Gas Information. Paris, OECD Publishing.

IEA. (2014) "What Are the Methods of Calculation of Primary Energy Equivalent? (Web page)." http://www.iea.org/statistics/.

INE. (2013) “Consumo de energia associado às emissões.” http://www.ine.pt/.

Jackson R. and Murray A. (2004) Alternative Input-Output Matrix Updating Formulations. Economic Systems Research, 16, 135-148.

Leite A.N. (2010) A Internacionalização Da Economia Portuguesa. Relações Internacionais, 12, 119-132. (in Portuguese).

Liu N. and Ang B.W. (2007) Factors Shaping Aggregate Energy Intensity Trend for Industry: Energy Intensity Versus Product Mix. Energy Economics, 29, 609-635.

Lourtie P. (2012) Understanding Portugal in the Context of the Euro Crisis. In: W.R. Cline and G. Wolff (eds.) Resolving the European Debt Crisis: Special Report 21. Brussels, Peterson Institute for International Economics.

Mata E. and Valério N. (2003) História Económica de Portugal: Uma Perspectiva Global. Lisbon, Editorial Presença. (in Portuguese).

Mendiluce M., Pérez-Arriaga I., and Ocaña C. (2010) Comparison of the Evolution of Energy Intensity in Spain and in the EU15: Why is Spain Different? Energy Policy, 38, 639-645.

Miller R.E. and Blair P.D. (2009) Input-Output Analysis: Foundations and Extensions (2nd ed.). Cambridge, Cambridge University Press.

Pinheiro Alves R. and Oliveira da Silva T. (2011) Políticas públicas de energia em portugal. Gabinete de Planeamento, Estratégia, Lisbon, Avaliação e Relações Internacionais. (in Portuguese).

Robaina Alves M. and Moutinho V. (2013) Decomposition Analysis and Innovative Accounting Approach for Energy-Related $\mathrm{CO}_{2}$ (Carbon Dioxide) Emissions Intensity Over 1996-2009 in Portugal. Energy, 57, 775-787.

Robert J. and Lennert M. (2010) Two Scenarios for Europe: Europe Confronted with High Energy Prices or Europe After Oil Peaking. Futures, 42, 817-824.

Rodrigues J. and Reis J. (2012) The Asymmetries of European Integration and the Crisis of Capitalism in Portugal. Competition \& Change, 16, 188-205.

Rodrigues J.F.D. and Rueda-Cantuche J.M. (2013) A Two-Stage Econometric Method for the Estimation of Carbon Multipliers With Rectangular Supply and Use Tables. Ecological Economics, 95, 206-212.

Rose A. and Casler S. (1996) Input-Output Structural Decomposition Analysis: A Critical Appraisal. Economic Systems Research, 8, 33-62.

Rosenthal E. (2010) Portugal gives itself a clean-energy makeover. The New York Times, 2010 (August 10): A1.

Scholtens B. and Yurtsever C. (2012) Oil Price Shocks and European Industries. Energy Economics, 34, 1187-1195.

Seibel S. (2003) Decomposition Analysis of Carbon Dioxide Emission Changes in Germany: Conceptual Framework and Empirical Results. Wiesbaden, Federal Statistical Office of Germany.

Serrenho A. (2013) Useful Work as and Energy End-use Accounting Method: Historical and Economic Transitions and European Patterns. Ph.D. thesis, University of Lisbon, Lisbon.

Serrenho A., Sousa T., Warr B., Ayres R., and Domingos T. (2014) Decomposition of Useful Work Intensity: The EU (European Union)-15 Countries from 1960 to 2009. Energy, 76, 704-715.

Serrenho A., Warr B., Sousa T., Ayres R., and Domingos T. (2015) Structure and Dynamics of Useful Work Along the Agriculture-Industry-Services Transition: Portugal from 1856 to 2009. Structural Change and Economic Dynamics. (In Press).

Strømman A.H., Peters G.P., and Hertwich E.G. (2009) Approaches to Correct for Double Counting in Tiered Hybrid Life Cycle Inventories. Journal of Cleaner Production, 17, 248-254.

Su B. and Ang B.W. (2012a) Structural Decomposition Analysis Applied to Energy and Emissions: Some Methodological Developments. Energy Economics, 34, 177-188.

Su B. and Ang B.W. (2012b) Structural Decomposition Analysis Applied to Energy and Emissions: Aggregation Issues. Economic Systems Research, 24, 299-317. 
Suh S. (2009) Handbook of Input-Output Analysis Economics in Industrial Ecology. New York, Springer.

ten Raa T. and Rueda-Cantuche J.M. (2003) The Construction of Input-Output Coefficients Matrices in an Axiomatic Context: Some Further Considerations. Economic Systems Research, 15, 439-455.

UN (1982a) Concepts and Methods in Energy Statistics with Special Reference to Energy Accounts and Balances. New York, United Nations.

UN (1982b) Concepts and Methods in Energy Statistics with Special Reference to Energy Accounts and Balances. New York, United Nations.

UN (1993) System of National Accounts 1993. New York, United Nations.

UN (1999) Handbook of Input-Output Table Compilation and Analysis. New York, United Nations.

UN (2009) System of National Accounts 2008. New York, United Nations.

Varandas Ferreira P.F. (2013) Electricity Power Planning in Portugal: The Role of Wind Energy. Ph.D. thesis, University of Minho.

Voigt S., De Cian E., Schymura M., and Verdolini E. (2014) Energy Intensity Developments in 40 Major Economies: Structural Change or Technology Improvement?. Energy Economics, 41, 47-62.

Wachsmann U., Wood R., Lenzen M., and Schaeffer R. (2009) Structural Decomposition of Energy Use in Brazil from 1970 to 1996. Applied Energy, 86, 578-587.

Weber C.L (2009) Measuring Structural Change and Energy Use: Decomposition of the US Economy from 1997 to 2002. Energy Policy, 37, 1561-1570.

Weidema B., Ekvall T., and Heijung R. (2009) "Guidelines for Application of Deepened and Broadened LCA.” Deliverable D18, CALCAS Project, Leiden. http://www.calcasproject.net/.

Wood R. (2009a) Structural Decomposition Analysis of Australia's Greenhouse Gas Emissions. Energy Policy, 37, 4943-4948.

Wood R. (2009b) Construction, Stability and Predictability of an Input-Output Time-Series for Australia. Economic Systems Research, 23, 175-211.

Xu Y. and Dietzenbacher E. (2014) A Structural Decomposition Analysis of the Emissions Embodied in Trade. Ecological Economics, 101, 10-20. 